\title{
EDITORIAL
}

\section{El lago Chinchaycocha en el mercado de bonos de carbono}

El cambio climático como fenómeno global preocupa a todo el mundo y se manifiesta en lo cotidiano a través de diversos desórdenes del clima. El Panel Intergubernamental de Cambio Climático (IPCC), en su cuarto informe de evaluación presentado el 2007, y la Organización Mundial de Meteorología (OMM) han establecido que desde el 2001 la temperatura media global en el planeta registra el nivel de aumento más alto de nuestra historia. A este ritmo, y por lo difícil que resulta encontrar una solución aun en el mediano plazo, todo indica que el 2013 no será la excepción.

Las causas del cambio climático son atribuidas a factores naturales pero también antropogénicos; existe ya consenso respecto a la influencia de los gases de efecto invernadero (GEI), sobre todo el dióxido de carbono $\left(\mathrm{CO}_{2}\right)$ en este proceso acelerado de calentamiento del planeta.

Esta crisis del clima, como una forma de ser enfrentada, hoy está obligando a los países a promover proyectos que reduzcan las emisiones de GEl y permitan el almacenamiento de carbono. Uno de los mecanismos internacionales establecidos para concretar este objetivo son los bonos de carbono, iniciativa dispuesta por el Protocolo de Kioto, acuerdo jurídicamente vinculante firmado en 1997 y en vigor desde el 2005. Expiró el año pasado, pero la histórica Conferencia de Doha, Catar, decidió en diciembre último prorrogar la vigencia del tratado hasta el 2020.

El protocolo, en su primera fase, exige a las grandes potencias reducir durante el período 2008-2012 la emisión de gases en un 5,2\% por debajo del nivel de 1990. Lo interesante es que las empresas de tales potencias, para cumplir esta obligación, pueden hacerlo en cualquier lugar o comprar bonos de carbono de países que superen las metas exigidas. La emisión de estos bonos es, después de todo, una iniciativa de descontaminación, que permite que los países industrializados sigan con sus prácticas contaminantes, en tanto invierten capitales en los países subdesarrollados para reducir en su favor las emisiones de GEI.

Esta iniciativa ha generado un mercado de compra y venta de certificados de emisiones reducidas (CER). Nuestro país tiene enormes posibilidades para captar estos recursos. Se trata, entonces, de una oportunidad para ingresar a este mercado y generar importantes recursos que pueden ser invertidos en mayor investigación, desarrollo e innovación $(I+D+i)$ en los mismos procesos de adaptación y mitigación del cambio climático.

Perú tiene 13 humedales reconocidos y protegidos por la convención Ramsar, uno de estos humedales es el lago Chinchaycocha - el segundo más extenso del país - que debe ser visto hoy como un ecosistema que brinda servicios ambientales diversos y su conservación por lo tanto debe darse en el ámbito del mercado de bonos de carbono. Es la razón por la que en esta oportunidad con fines de determinar su potencial capacidad de almacenamiento de carbono, la Universidad Continental con el apoyo del Servicio Nacional de Áreas Naturales Protegidas por el Estado (SERNANP) ha desarrollado entre los años 2011 y 2012 el importante proyecto de investigación "Almacenamiento de carbono en especies predominantes de flora en el lago Chinchaycocha" y así tener a futuro una adecuada valoración de este humedal en estos tiempos en que su conservación responsable es clave para la adaptación y mitigación al cambio climático.

La revista científica Apuntes de Ciencia \& Sociedad en este número expresa especial interés en poner a disposición de la comunidad científica y académica los resultados del mencionado proyecto de investigación como muestra de nuestro compromiso con la ciencia y la vida.

Wilfredo Bulege

Editor 